\title{
COMPARATIVE STUDY ON THE FUNDAMENTAL TIME PERIOD OF RCBUILDINGS BASED ON CODAL PROVISION AND AMBIENT VIBRATION TEST - A CASE STUDY OF KATHMANDU VALLEY
}

\author{
Ramila Shrestha, Sudip Karanjit \\ Department of Civil Engineering, Khwopa Engineering College, Libali-8, Bhaktapur, Nepal
}

\begin{abstract}
For the proper design of any structure, its fundamental properties should be known. The fundamental time period is a primary consideration for seismic design. Generally empirical relations given by code are used in design of building structure, where time period is the function of height and lateral dimension in most cases. But, these empirical relations given by codes are not verified in the context of Nepal. For existing structures, in addition to code formulas and available analytical tools, such as modal analyses, various methods of testing, including ambient and forced vibration testing procedures may be used to determine fundamental time period. In this study, the fundamental period of the $31 \mathrm{RC}$ infill buildings located in Kathmandu valley was identified using ambient motions recorded at each building. Ambient vibration measurements of buildings have been performed by using geophone. Fundamental time periods evaluated experimentally and calculated by different codal formulas were compared. Single variable regression analysis was done, and time period in relation with height is evaluated. In this analysis, codal time period was found higher than experimental one. Multi-variable regression analysis was also done, and the relation between time period, height and lateral dimension was formulated. From multivariable regression formulation, it was concluded that the effect of base dimension of building to fundamental time period is very less. It can be concluded that the fundamental time period of RC building in our current practice can be better correlated by height only relation $\left(\mathrm{T}=\mathrm{CH}^{\mathrm{a}}\right)$ than by height and base-dimension relation ( $\mathrm{T}$ $=\mathrm{C} \frac{H}{\sqrt{D}}$ ) given by code. Fundamental time period calculated from codal formula for RC building with infill and from experiment was found near in most cases.
\end{abstract}

Keywords: Ambient vibration, fundamental time period, Fast Fourier Transform(FFT), geophone, RC building

\section{Introduction}

The dynamic characteristics of buildings play an important role in predicting their seismic behavior and in selecting the appropriate retrofitting approach in case of damage. The fundamental vibration period of a building appears in the equation specified in building codes to calculate the design base shear and lateral forces. To estimate the period, building codes provide empirical formulas that depend on the building material (steel, RC etc.), building type (frame, shear wall, etc.), and overall dimensions.

\footnotetext{
*Corresponding author: Ramila Shrestha

Department of Civil Engineering, Khwopa Engineering College, Libali-8, Bhaktapur, Nepal

Email:ramilashrestha25@gmail.com

(Received: 2016 Nov 10 Accepted: 2016 Nov 29)
}

Researchers and earthquake codes have provided expressions for estimating the fundamental period of a building which is a function of the total height or the number of storey in most cases. In general, the empirical expression for fundamental natural period of RC MRF buildings, used in seismic codes across the world is

$\mathrm{T}=\mathrm{CH}^{\mathrm{a}}$

where,

$\mathrm{H}=$ the total height of the building in meters

Cand $\mathrm{a}=$ constant coefficients

In most of the cases ' $a$ ' is taken as $3 / 4$.

The value of ' $\mathrm{C}$ ' is adopted different by various code. 
This particular form of semi empirical formulae was theoretically derived using the Rayleigh's method with the assumptions that the equivalent static lateral forces are distributed linearly over height of the building, the distribution of stiffness with height produces a uniform storey drift under the linearly distributed lateral forces, the base shear is inversely proportional to $\mathrm{T}^{2 / 3}$, and the deformations are controlled by the drift limitstate. According to NBC $105: 1994$, C is taken 0.06. According to IS 1893(part1):2002, Uniform Building Code (UBC, 1997), the European seismic design regulation, Eurocode 8 (CEN, 2004), and the National Building Code of Canada (NBCC, 2005), $\mathrm{C}$ is taken 0.075. According to Applied Technological Council of 1978 (ATC3-06, 1978) C is taken to be 0.03 for $\mathrm{RC}$ moment-resisting frames. The numerical value of the constant Cwas obtained from the measured periods of buildings during the 1971 San Fernando earthquake. In this case, $\mathrm{H}$ represents the building height measured in feet.

NBC 105:1994, IS 1893(part1):2002, other seismic building codes including the Egyptian, the Venezuelan and the French Seismic Codes, in addition to the building's height $\mathrm{H}$ (in meters), take into consideration the total base dimension, $\mathrm{D}$ (in meters), for the infill $\mathrm{RC}$ frame. The expression for the estimation of the fundamental period of vibration from the aforementioned seismic codes is

$\mathrm{T}=0.09 \frac{H}{\sqrt{D}}$

Modal identification of existing buildings through the analysis of in-situ vibration measurements became a classic procedure for providing modal characteristics of a building, for studying the seismic response of buildings and even for damage detection. Modal characteristics are often identified from ambient vibration measurements and from seismic records. Ambient vibration testing is generally preferred to non-destructive vibration measurement techniques for obtaining the modal parameters of large structures. Ambient vibration measurements of buildings to obtain natural period of buildings, have been employed in USA since 1925 (USDC, 1936). The ambient vibration time histories are recorded in building and Fourier Spectrum of each of the signals are obtained, and natural frequencies are derived from these. Since the energy required to deform the structure in the fundamental mode of vibration is the least, the contribution of fundamental mode is dominant in the ambient vibration response of the structure. Thus the approach of deriving dynamic characteristics of a structure by ambient vibration measurement is considered adequate only for ascertaining the properties with fundamental mode of vibration. A structure can be adequately excited by wind, traffic, and human activities and the resulting motions can be readily measured with highly sensitive instruments. Ambient vibration measurements of many buildings have been recorded across the world in the past to fundamental modes of vibration, (Michel et al., 2008). It is also recognized that the experimental data from one region may not be used in another owing to the differences in the construction methods and materials (Crawford and Ward, 1964).Also the ambient vibration-based techniques were as accurate as active methods for determining vibration modes and much easier to implement for a large set of buildings (Trifunac, 1972).

Chiauzzi, et al.(2012) studied the fundamental period of a group of RC buildings located in the cities of Victoria and Vancouver (British Columbia, Canada)and showed that building periods estimated based on simple equations provided by earthquake design codes in Europe EC8(CEN-2003) and North America (UBC97 and NBCC-2005) are significantly greater than the periods computed using ambient vibration records on the monitored buildings. Tarek M. Alguhane (2015) identified the dynamic properties of the 32 buildings located in the Madinah of Saudi Arabia using ambient motions recorded at several, spatially-distributed locations within each building. The periods of existing buildings are shorter than that given by most empirical code formulas.

Goel and Chopra (1997) studied 27 Reinforced Concrete (RC) MRF buildings in California derived from their recorded motions during several earthquakes starting with the 1971 San 
Fernando earthquake. Periods in two orthogonal lateral directions were measured and the equation relating period ' $\mathrm{T}$ ' to height ' $\mathrm{H}$ ' of the building was derived from regression analysis and recommended as

$\mathrm{T}=0.016 \mathrm{H}^{0.9}$

Where, $\mathrm{H}$ is in feet

\section{Experimental Study}

\subsection{Building Selection}

Buildings which can be easily accessible and having different heights were collected for the study. Only designed RC frame buildings of Kathmandu valley with partial brick infill were selected. 31 buildings ranging from 3 to 18 storey, free standing buildings i.e. not attached to any other buildings were taken for the study.

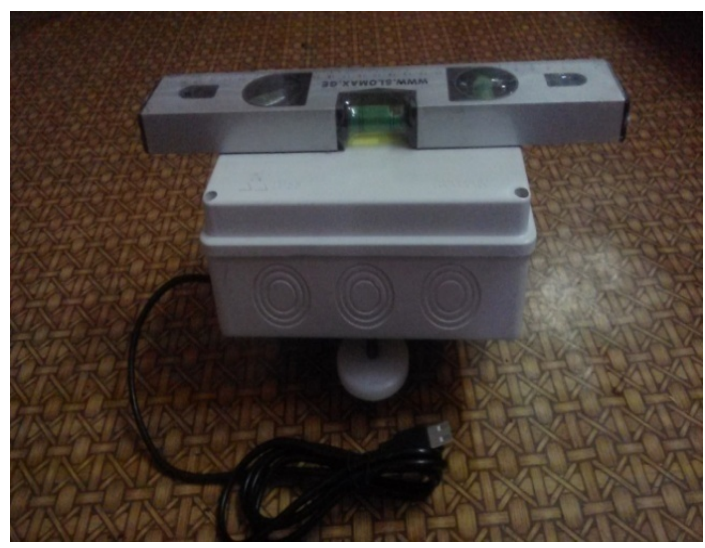

Fig1 Geophone used in this study

\subsection{Data Collection}

The 3-component $4.5 \mathrm{~Hz}$ Geophone (Fig 1) was used for data collection. Vibration data of building in two horizontal direction and one vertical direction were collected using the device for each sample (Fig 2). The instrument was set up on the top floor of the building almost at the centre of the plan dimension. The instrument was fixed aligning its east-west direction parallel to the length of the building and north-south direction parallel to breadth of the building. Then, the instrument was leveled and started to record the data using Thermino_Hal software. Data was collected for 15 minutes with data acquisition frequency of $500 \mathrm{~Hz}$. Drawings of the buildings were also collected for plan dimensions and height of the building.

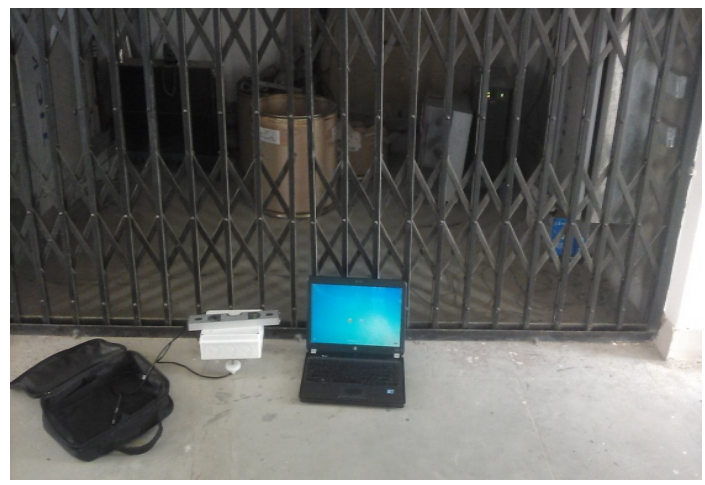

Fig 2 Data collection at site (typical)

\subsection{Data Processing}

Data collected by the instrument was transferred to Geopsy software for processing. Then the time domain data collected by the instrument was converted into frequency domain data by fast Fourier transform algorithm present in the software. As in frequency spectrum, clear peaks were obtained and noise and disturbances are very little; no filter was used. Also, frequency values from spectrum with or without filter were not found different so data without filter were used for analysis.

\subsection{Data Analysis}

From frequency spectrum (Fig 5), frequency for peak amplitude in both east-west and north-south direction were found out for each sample. Vertical vibration was not considered. Then, for each sample fundamental time period in both directions were evaluated for those frequencies. Codal time period was also calculated and compared with the experimental period.

\subsection{Single Variable and Multi Variable Regression Analysis}

For single variable regression analysis, time period vs. height of the building data were plotted, and curve was fitted in linear and power form. Curve was also plotted for codal relation and compared with experimental one. 


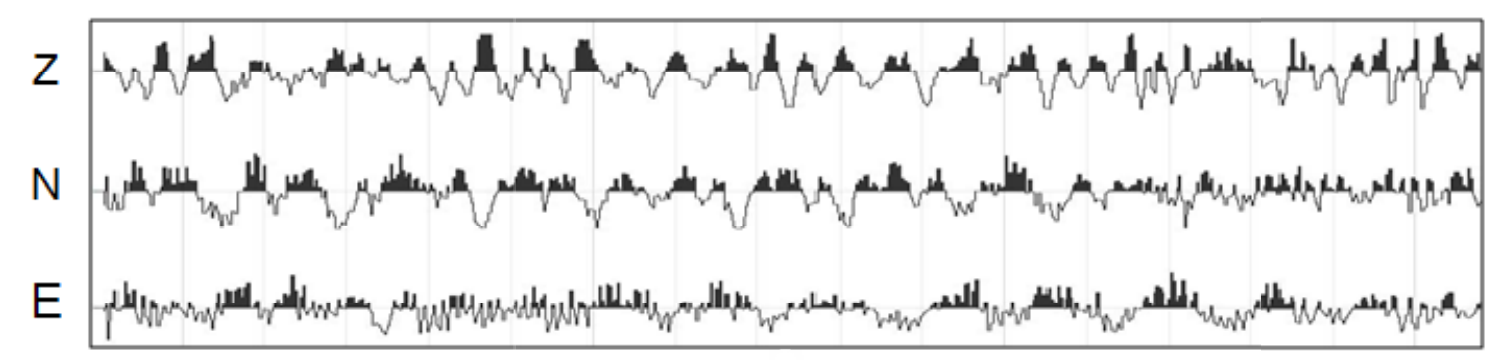

Fig 4 Sample of time domain data taken by geophone

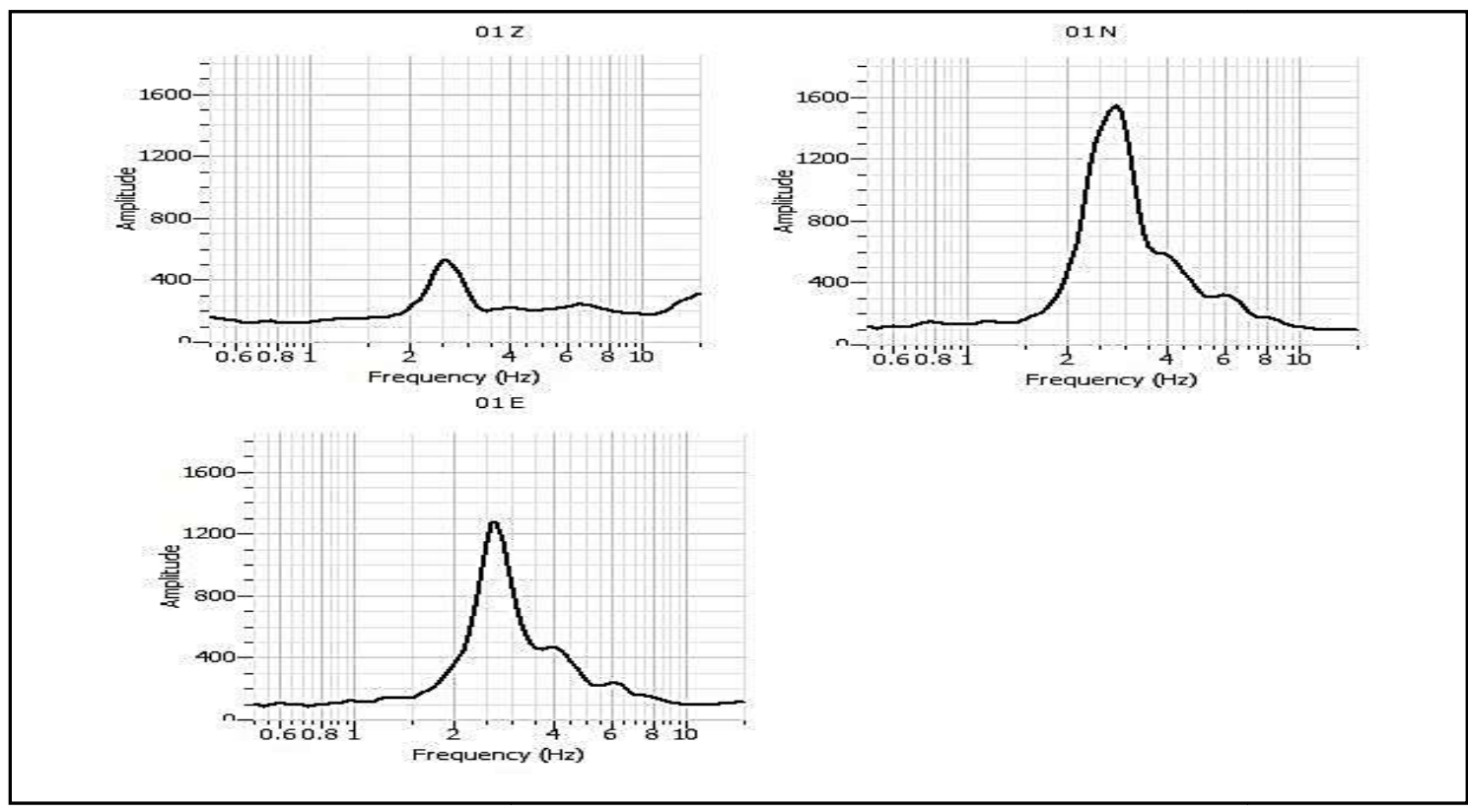

Fig 5 Frequency spectrum of a sample (typical)

For multivariable regression analysis, a simple spreadsheet program had been developed, and Time period in relation with height and width of the building was formulated.

\section{Results and Discussions}

Time period obtained from the processed data of all the buildings has been co-related using regression analysis. Co-relation of time period with height as well as base dimension of the building have been carried out, and, they were also compared with current codal provision (IS 1893:2002)

1. Correlation between time period and building height from regression analysis has been obtained as (Fig 6 and Fig 7):

$\mathrm{T}=0.012 \mathrm{H}^{1.134}$

$\mathrm{R}^{2}=0.88$ (obtained from power regression)
$\mathrm{T}=0.02 \mathrm{H}-0.003$

$\mathrm{R}^{2}=0.80$ (obtained from linear regression)

$\mathrm{T}=0.05 \mathrm{H}^{0.75}$

$\mathrm{R}^{2}=0.78$ (obtained from power regression with fixed value of power of $\mathrm{H}$ )

2. Correlation between Time period, building height and base dimension from regression analysis has been obtained as (Fig 8):

$\mathrm{T}=0.03 \mathrm{H}^{0.94} / \mathrm{d}^{0.04}$

$\mathrm{R}^{2}=0.81$ (obtained from power regression)

$\mathrm{T}=0.093 \frac{H}{\sqrt{D}}$

$\mathrm{R}^{2}=0.65$ (obtained from power regression with fixed value of power of $\mathrm{H}$ and $\mathrm{D}$ ) 


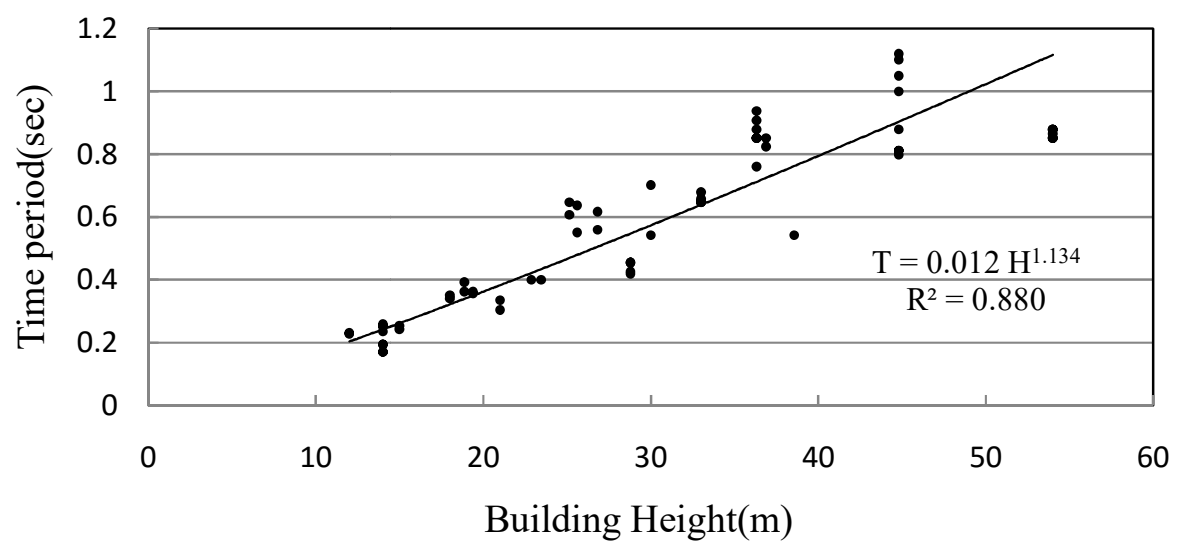

Fig 6 Experimental period-height relation by single variable power regression

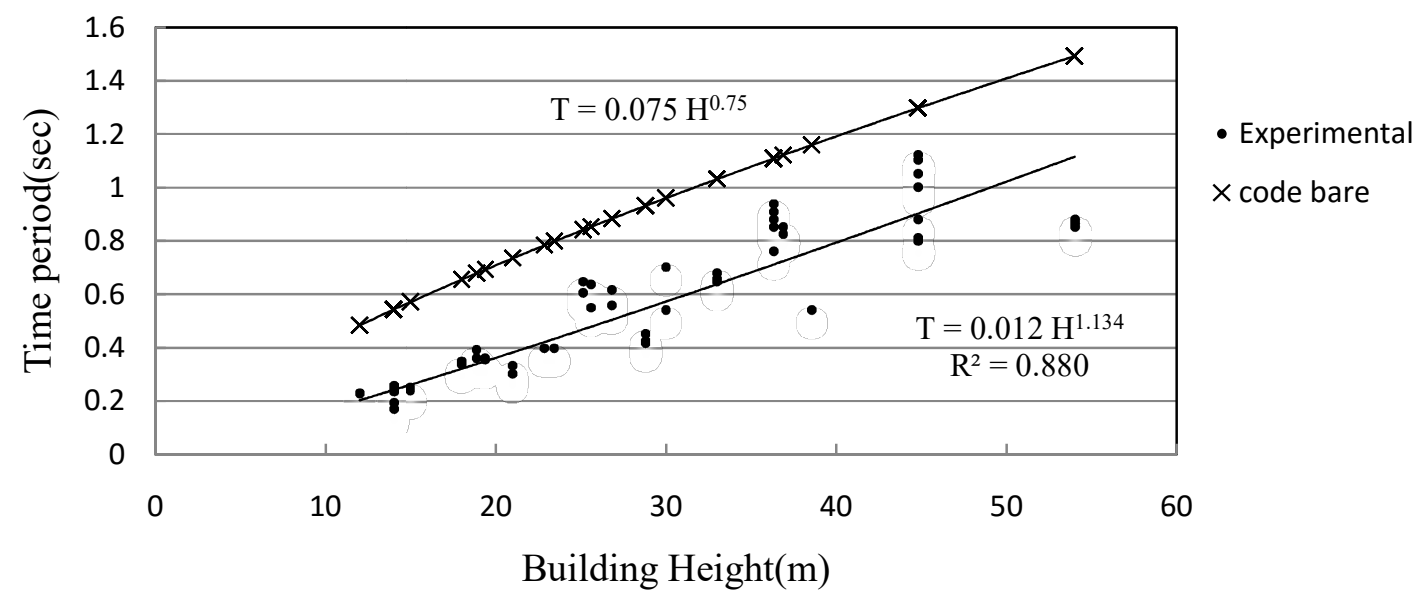

Fig 7 Experimental andcodal time period - height relation by single variable power regression

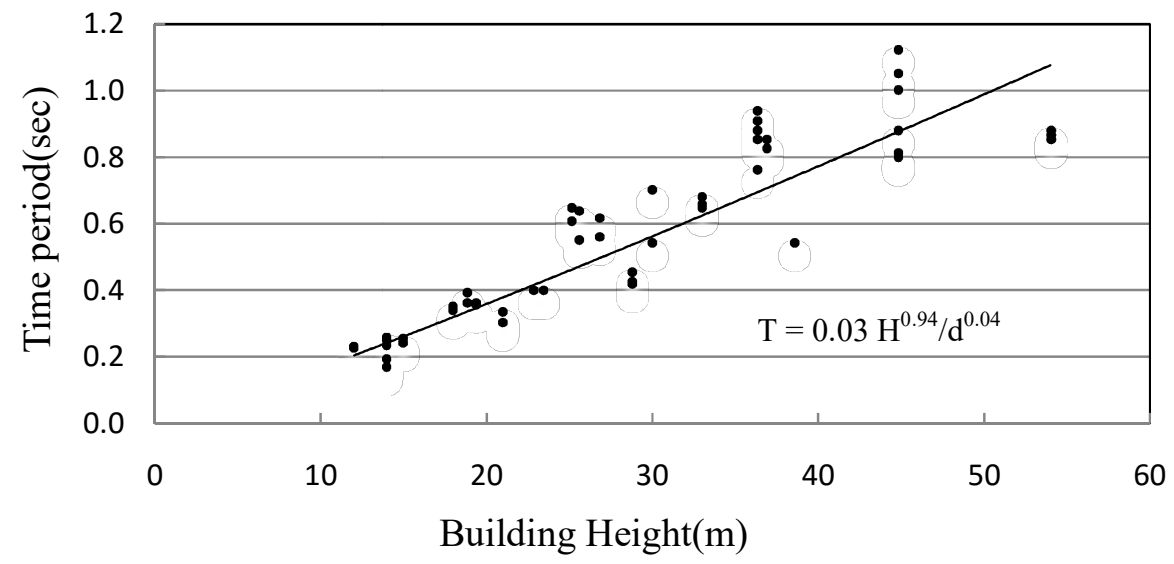

Fig 8 Experimental period - height relation by multivariable regression 
3. Comparison between experimental time period and codal time period (infill)

On comparison of regression relation with codal relation, experimental time period is found similar with codal period for low rise buildings upto about $24 \mathrm{~m}$ height and above $24 \mathrm{~m}$ height, with increase in height experimental periods were found more deviated from the codal period (Fig 9).
4. Percentage variation between experimental and codal time period (Building with infill)

The percentage difference chart has showed that fundamental time period calculated from codal formula and from experiment for RC frame with infill was not found very much different. In most of the cases $10 \%-30 \%$ while in few cases variation is upto $100 \%$ (Fig 10).

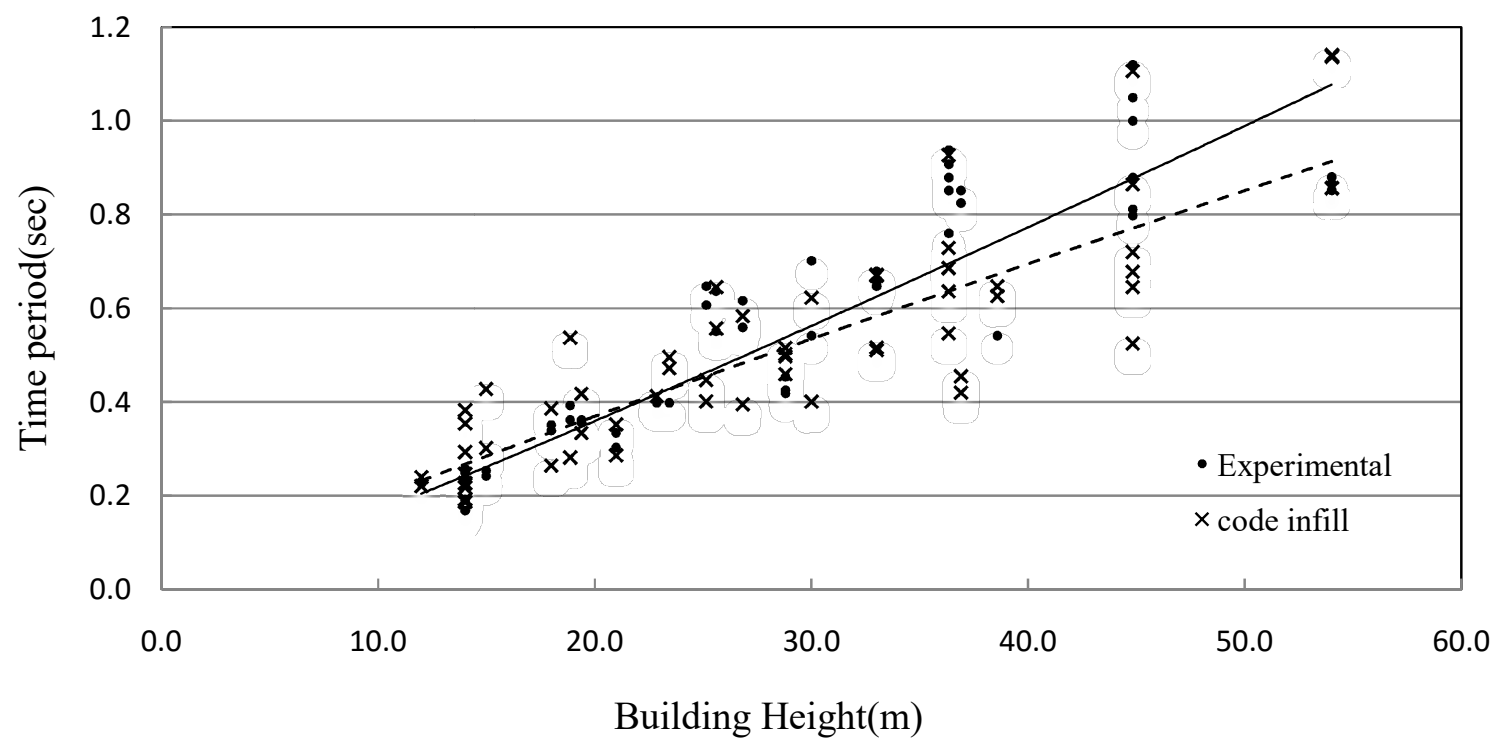

Fig 9 Comparison of codal and experimental time period (infill)

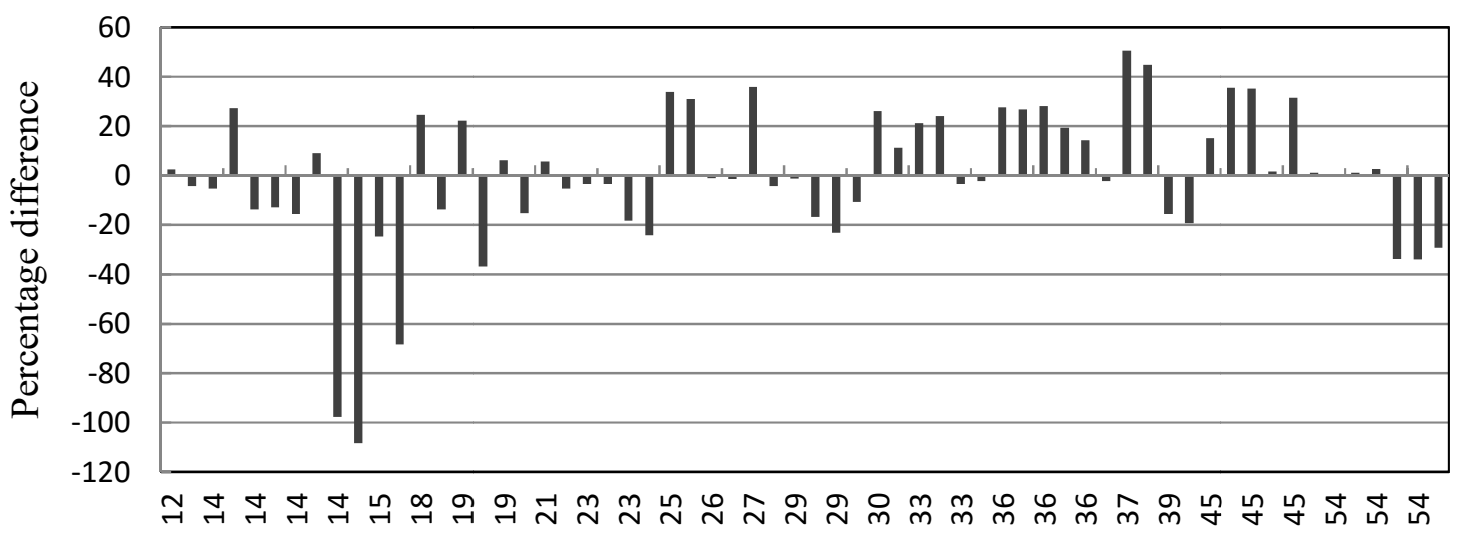

Building height(m)

Fig 10 Percentage difference between experimental and codal time period (infill) for individual building 


\section{Conclusion}

From this research work following conclusions has been drawn

1. Fundamental time period calculated from codal formula and from experiment for RC frame with infill was not found very much different. This indicates the current codal formula given by IS1893:2002 for RC infill frame can be approximately accepted.

2. The effect of base dimension of the building on the fundamental time period has been found less. So, the time period of RC MRF buildings with infill in our current practice can also be effectively co-related with height only.

3. Experimental time period has been found similar with codal period for low rise buildings (upto about $24 \mathrm{~m}$ height) and greater than codal period for high rise buildings (above $24 \mathrm{~m}$ height) with the more deviating order with increase in height. This indicates the underestimation of timeperiod of high rise building by current codal provision in most of the cases.

\section{References}

[1] Applied Technological Council. (1978). Tentative provisions for the development of seismic regulations for buildings. Rep. No. ATC3-06. Applied Technological Council. Palo Alto, Calif.

[2] Bureau of Indian Standards, Indian standard criteria for earthquake resistant design of structures - part 1: general provisions and buildings, Tech. Rep. IS1893, Bureau of Indian Standards, New Delhi, India, 2002, Fifth Revision.

[3] Chiauzzi, L., Masi, A., Mucciarelli, M., Cassidy, J., Kutyn, K., Traber, J., et al. (2012). Estimate of fundamental period of reinforced concrete buildings: code provision vs experimrntal measures in victoria and Vancouver(BC, Canada).

[4] Crawford, R., \& H.S.Ward. (1964). Determination of the natural period of buildings. Bulletin of the seismological society of America, vol.54 .

[5] Egyptian Seismic Code, Regulations for Earthquake Resistant Design of Buildings in Egypt, Egyptian Society for EarthquakeEngineering, Cairo, Egypt, 1988.
[6] European Committee for Standardization CEN, "Eurocode 8: Design of structures for earthquake resistance - part 1: general rules, seismic actions and rules for buildings," EuropeanStandard EN 19981:2004, 2004.

[7] Goel, R., \& Chopra, A. K. (1997). Period formulas for moment resisting frame buildings. journal of structural Engineering,vol123.

[8] Michel, C., Gueguen, P., \& Bard, P. (2008). Dynamic parameters of structures extracted from ambient vibration measuremen. Soil dynamics and earthquake engineering vol-28.

[9] National Research Council, The National Building Code of Canada (NBCC), National Research Council, Ottawa, Canada, 1995.

[10] Nepal National Building Code 105(1994). Seismic design of building in Nepal.

[11] Tarek M. alguhane, A. H. (2015). Ambient vibration testing of existing buildings Madinah. International Journal of Civil, Environmental,Structural, Construction and Architectural Engineering vol. 9.

[12] Trifunac, M. D. (1972). Comparision between ambient and forced vibration experiments. Earthquake engineering and structural dynamics,vol.1.

[13] Uniform building code. (1997). International Conference of Building Officials, Whittier, Calif.

[14] USDC. (1936). Earthquake investigtions in California, 1934-1935, special publications No. 201. Washington,Dc,USA: United states department of commerce.

[15] Venezuelan Seismic Code, Regulations for Earthquake Resistant Buildings, Comision De Normas Industriales, Covenin, Caracas,Venezuela, 1988. 